\title{
Translation and cross-cultural adaptation of the World Health Organization Disability Assessment Schedule - WHODAS 2.0
}

Tradução e adaptação transcultural do World Health Organization Disability Assessment Schedule - WHODAS 2.0

\author{
Traducción y adaptación transcultural de la World Health Organization Disability \\ Assessment Schedule - WHODAS 2.0
}

Shamyr Sulyvan Castro', Camila Ferreira Leite ${ }^{2}$

\begin{abstract}
The World Health Organization (WHO) planned a new functioning assessment tool - the WHODAS 2.0 (World Health Assessment Disability Schedule 2.0) - a user-friendly application instrument based on the theoretical framework of the ICF. The aim of this article is to introduce the Brazilian version of WHODAS to clinical and academic users interested in the assessment of functioning. The process was conducted according to the Translation Package offered by $\mathrm{WHO}$, in addition to the permission for translating the tool. Three translators worked in this research to produce the definitive version of the manual and a set of linguistic evaluation forms. Finally, the Brazilian version was approved by WHO. All documents about WHODAS were translated and are free to download on the internet. WHODAS 2.0 addresses functioning according to the ICF domains and keeps the multifactorial and biopsychosocial perspective of the phenomenon. As it has an ICF differentiate presentation, the data collection is faster (20 minutes, on average) and more objective. Besides, it was planned to be a generic and transcultural tool. WHODAS was translated and is available on Internet to use. It is expected that the use of WHODAS will be widespread in Brazil, in clinical and research settings, aiming at the biopsychosocial approach of the functioning, as endorsed by WHO.
\end{abstract}

Keywords | Functioning; Translation.
RESUMO |A Organização Mundial da Saúde (OMS) planejou uma nova ferramenta de aferição da funcionalidade - o WHODAS 2.0 (World Health Assessment Disability Schedule 2.0) - um instrumento de aplicação facilitada e baseado no modelo teórico da CIF. Este artigo busca introduzir a versão brasileira do WHODAS para usuários clínicos e acadêmicos interessados na aferição da funcionalidade. O processo foi conduzido de acordo com o Translation Package, oferecido pela OMS, junto com a permissão para tradução do material. Três tradutores trabalharam nesse projeto para produzir a versão final do manual e um conjunto de formulários de avaliação linguística. Em seguida, a versão brasileira foi aprovada pela OMS. Todos os documentos sobre o WHODAS foram traduzidos e estão disponíveis gratuitamente na internet. WHODAS 2.0 aborda a funcionalidade de acordo com os domínios da CIF e mantém a perspectiva multifatorial e biopsicossocial. Como diferencial da CIF, a coleta de dados com o WHODAS é mais rápida (aproximadamente 20 minutos) e mais objetiva. Além disso, ele foi planejado para ser uma ferramenta genérica e transcultural. WHODAS foi traduzido e disponibilizado na internet. É esperado que o uso do WHODAS se dissemine pelo país, em ambientes clínicos e de pesquisa, buscando a abordagem biopsicossocial da funcionalidade, conforme endossado pela OMS.

Decritores | Funcionalidade; Tradução.

Research developed at the Department of Applied Physical Therapy of the Universidade Federal do Triângulo Mineiro (UFTM) Uberaba (MG), Brazil.

'PhD in Health Sciences from the Faculdade de Saúde Pública (FSP - USP). São Paulo. Professor. Department of Physical Therapy of the Universidade Federal do Ceará (UFC) - Fortaleza (CE), Brazil.

${ }^{2} \mathrm{PhD}$ in Health Sciences from the Universidade Federal do Triângulo Mineiro (UFTM). Uberaba. Professor. Department of Physical Therapy of the Universidade Federal do Ceará (UFC) - Fortaleza (CE), Brazil. 
RESUMEN I La Organización Mundial de la Salud (OMS) planeó una nueva herramienta de medición de la funcionalidad, la WHODAS 2.0 (World Health Assessment Disability Schedule 2.0) -un instrumento de aplicación basado en el modelo teórico de la CIF. Este artículo busca introducir la versión brasileña de la WHODAS para los usuarios clínicos y académicos interesados en la medición de la funcionalidad. Se realizó el proceso de acuerdo al Translation Package, ofrecido por la OMS, en asociación con el permiso para traducir el material. Tres traductores trabajaron en este proyecto para producir la versión final del manual y un conjunto de formularios de evaluación lingüística. Luego, OMS aprobó la versión brasileña. Todos los documentos sobre
WHODAS han sido traducidos y están disponibles libremente en Internet. WHODAS 2.0 trata de la funcionalidad de acuerdo a los dominios de la ICF y mantiene la perspectiva multifactorial y biopsicosocial. Es un diferencial de la ICF la recolección más rápida de datos con el WHODAS (aproximadamente 20 minutos) y más objetiva. Además, ha sido planeado para ser una herramienta genérica y transcultural. WHODAS ha sido traducida y está disponible en Internet. Se espera que el uso de la WHODAS se propague en el país, en ambientes clínicos y de investigación, buscándose en abordaje biopsicosocial de la funcionalidad, según lo endosado por la OMS

Palabras clave | Funcionalidad; Traducción.

\section{INTRODUCTION}

According to the World Health Organization (WHO), functioning is a concept that covers body functions and structures, activities, and participation. Disability is related to impairments, activity limitations, and participation restrictions ${ }^{1}$. Functioning and disability assessments have been under discussion since different definitions can result in miscellaneous information ${ }^{2-4}$.

Aiming to offer a standard definition to be used around the world, the WHO published the International Classification of Functioning, Disability, and Health - ICF, proposing to use the biopsychosocial model in understanding the functioning. The biopsychosocial model incorporates components of biomedical and social models, and conceives disability as a multidimensional process, involving body functions and structures, activities, participation, and the environmental and personal contexts of functioning ${ }^{5}$. Thus, ICF proposes functioning as an interactive process among its components health conditions, body functions and structures, activities, participation, and contextual (environmental and personal) factors ${ }^{6}$.

Beyond this theoretical and conceptual discussion, ICF is also composed by more than 1,400 classifiers codes to health status identification. However, considering its scope, the application of ICF can be time-consuming ${ }^{7}$ thus invalidating its effective use. Aiming to overcome this barrier, some ICF derivate tools with shorter application time were proposed by WHO, like the Core Sets ${ }^{8}$ and the Check List ${ }^{9}$. A third generic tool that incorporated the ICF framework (which assesses functioning by domains) was also proposed by WHO in 2010, the World Health Organization Disability Assessment Schedule - WHODAS 2.0 ${ }^{10}$.

For professionals related to the rehabilitation or functioning health, the use of a tool to assess functioning according to the ICF framework and with favorable applicability provides a faster functioning diagnosis, allowing more appropriate clinical interventions and based on the biopsychosocial model. Besides, the research field can benefit from having an instrument that is applicable to different functioning profiles. Furthermore, the possibility of numerically quantifying the functioning profile and its domains is also a strong point, since statistical comparisons can be made in pursuit of scientific evidence. For these reasons, this article aims to present the translated version of the World Health Organization Disability Assessment Schedule - WHODAS 2.0 to Brazilian Portuguese. This version is authorized and recognized by the World Health Organization - WHO.

\section{METHODOLOGY}

\section{Instrument}

WHODAS 2.0 was created by the WHO after ten years of collaborative research from scientists around the world. Originally developed to assess functioning, mainly in psychiatric patients, the first version of the instrument, called Disability Assessment Schedule WHO/DAS and published in 1988, has undergone considerable changes since its creation, culminating in the publication of WHODAS 2.0. The latter is a 
generic instrument, applicable to any health condition, physical disorders, mental or emotional problems, as well as drugs and alcohol addiction problems. Beyond the generic predicate, it has as a very positive point: the coverage of most ICF domains ${ }^{11}$.

The WHODAS development process consisted of a great international collaborative project and followed a study of protocols with cross-cultural applicability, which guaranteed a high degree of functional and metric equivalence between different cultures and environments ${ }^{11}$. The questions and answers scales of the instrument were chosen in distinct cultural centers, which carried out pilot tests and empirical field studies to develop and refine the instrument. So, at first, a 96-questions version was created, then, the questions were grouped into six domains to be used in field studies, using a multicenter design with standardized protocol in different countries around the world. In this step, the WHODAS was applied concurrently to other instruments as the Medical Outcome Study 12-item Short-Form Survey (SF12); the SF-36; the London Handicap Scale (LHS); WHOQOL (World Health Organization Quality of Life) or the WHOQOL-BREF. These initial field studies were designed to reduce the number of items on the questionnaire and to increase its reliability. At the end of this step, WHODAS was composed of 34 questions, and posteriorly, two other questions were added from the feedback offered by field interviewers as well as by a survey among experts ${ }^{11}$. Based on this instrument construction process, it should be clear to the reader that WHODAS 2.0 is not an ICF derived instrument, but an instrument that follows the ICF framework.

The seven versions of WHODAS, which differ as regards duration and/or mode of application, were published in $2010^{11}$. The complete version consists of 36 questions and the short version has 12 questions. The versions can be applied by an interviewer or self-administered, and there is still the possibility of applicating the questionnaire to a proxy. The short version is associated to a variance of $81 \%$ of the 36 -itens version, representing a good strategy for situations in which the time limit does not permit the application of the longer version ${ }^{11}$. The mean time of application of the short version is five minutes, and twenty minutes to the longer. Lastly, the $12+24$ version of WHODAS is a hybrid version of the other two. It uses the twelve questions to screen functioning domains with problems, allowing an increase in the amount of questions with the other 24 questions ${ }^{11}$. This hybrid version is offered in the interview form. All the WHODAS versions are for public use and can be found translated to several languages. Recently, the translated and cross-culturally adapted Brazilian version was accepted and recognized by the WHO.

The WHODAS Manual fundamentally presents a detailed overview of the instrument creation, pointing out the ICF conceptual substantiation that supports the domains of this functioning assessment tool. Besides that, it also presents the seven versions of WHODAS 2.0 and provides a comprehensive guide to properly apply its various versions. Reading of the manual is strongly encouraged by WHO for anyone who wish to use the WHODAS as a functioning assessment tool.

\section{Inter-institutional cooperation}

This translation and cross-cultural adaptation of WHODAS to the Brazilian Portuguese began after the consolidation of a cooperation agreement between the WHO and the Federal University of Triângulo Mineiro - UFTM (TR/14/017), signed in January 2014. By this cooperation document, the WHO assigned exclusively to UFTM and its researchers the right to translate and culturally adapt the Manual of WHODAS 2.0 as well as the seven versions of the instrument, with a twelvemonth total time - to conclude all the processes. The failure to meet this deadline means the return of the translation rights to $\mathrm{WHO}$, which could then transfer them to other institutions or researchers.

\section{Translation process}

After the formalization of the cooperation agreement and the granting of authorization for translation, WHO sent to the coordinator researcher of the translation project all material to be used in the translation and adaptation process. The set of documents sent was composed by the official version of the WHODAS 2.0 and its manual; a file called "Translation package"; and a language assessment form; furthermore, logos and standard types to be inserted in the translated version.

The Translation Package consists of a recommendation guide to be followed in the translation process. This guide is intended to standardize the translation process, allowing the researchers around 
the world to perform it with standardized and uniform methodology. Under this aspect, the guide to translation ensures that the versions from other languages reach adequate reliability levels, producing translated versions of high linguistic quality. According to the Translation Package, at the first step of translating, two bilingual translators worked independently in the translation of the material into Portuguese. Therefore, two translated versions into Portuguese were produced (Figure 1). Based on these two translated versions, the synthesis of both translations was made. At this step, the main researcher proceeded to compare the two translated versions and produced a conciliation version (Figure 1).

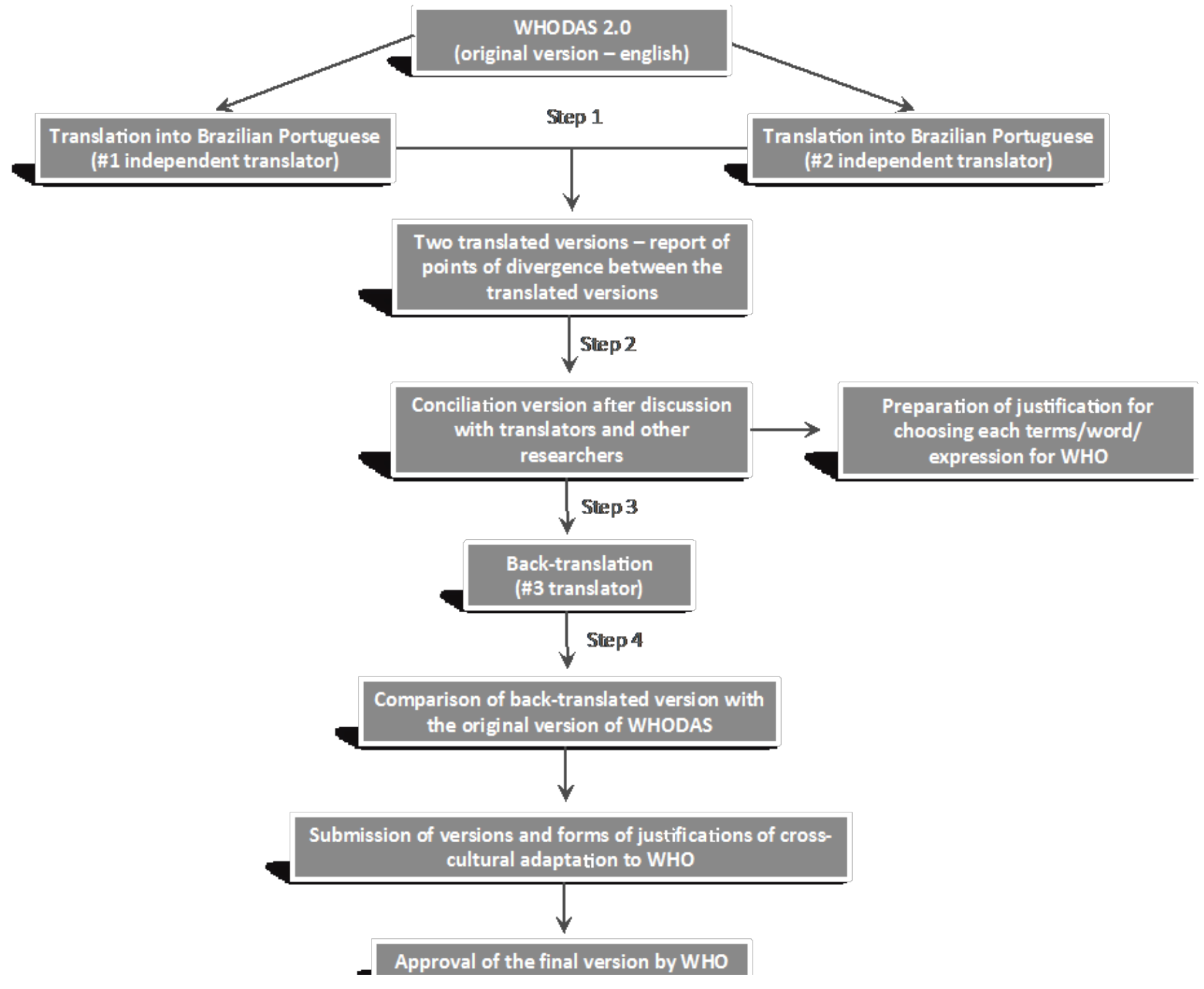

Figure 1. Steps of the translation and cross-cultural adaptation process of WHODAS 2.0 to use in Brazil

\section{Cross-cultural adaptation}

In the process of making the conciliation version, for each difference of words, terms or expressions made by the different translators, there was a selection of the best of them, after discussion with the group of researchers and translators involved in the first step. Every divergence was carefully recorded in linguistic evaluation forms. These forms contain specific fields to be filled with the location, language, and date on which 
the translation was being made. Then, the original term that had to be adapted and the final term were inserted. Besides that, there was a list with possible reasons for the need of cross-cultural adaptation: a) the item has a different meaning in the local usage of English than is intended in the WHO English version; b) the item is difficult or impossible to translate because there is no target language idiomatic equivalent, or no equivalent term; c) the item, when translated, has a meaning that is narrower than the original term. Only part of the connotations of the original term carry over into the target language; d) the item, when translated, has a meaning that is broader than the meaning in the original. The translated items have additional meanings that would change the interpretation of the item; e) the item can be translated, but there is a cultural applicability problem with the item, or with the definition, or with the examples used for the item. In addition to these options, there was still a space where other alternatives could be described. For each word, term or expression that needed some adjustment, a form was filled.

As a final product of the cross-cultural adaptation, we obtained the definitive version of WHODAS 2.0 in Brazilian Portuguese.

\section{Approval of the definitive version}

After adaptation, the third step of the process began. The material in Portuguese (reconciled version, produced in the step 2) was referred to another translator who had no relation to the other steps of the project or prior contact with the instrument originally written in English, so that the back-translation was performed (Figure 1). This process is also part of the Translation Package.

Finalized the back translation, the following documents were gathered and sent to WHO: 1) definitive version in Portuguese of the entire manual and questionnaires; 2) back-translation of the manual and all instruments; 3) comparative document of the two versions (translated and back-translated); 4) seventy-seven linguistic evaluation forms.

All the files were received by WHO at February 2015, for evaluation and approval. After approval and endorsement, the material was made available on the WHO website, along with versions translated into other languages. The Manual and the questionnaires can be accessed in the following websites <http://apps.who. int/iris/bitstream/10665/43974/19/9788562599514_ por.pdf> on the WHO repository.

\section{RESULTS}

For this article, we present in more detail only the version with 36 questions applied by an interviewer. However, it is noteworthy that other versions are also useful and valid, and can be obtained along with the manual on the website cited in the methods.

\section{The translated and cross-cultural adapted version of WHODAS 2.0, 36-items, applied by interviewer}

WHODAS 2.0 in the longer version (36 questions) is applied by an interviewer, and is also available to download from the Internet. In this version, following the ICF framework, WHODAS addresses the functioning according to the Domains: Cognition (6 questions); Mobility (5 questions); Self-care (4 items); Getting along (5 items); Life activities (4 questions); and Participation (8 items), totaling 36 questions. The reader will notice that in this version administered by interview, accompanying the instrument, are found two flash-cards used to assist interviewers, serving as reminders to respondents. The flash-card \#1 identifies the health conditions to be considered by the respondent, besides the difficulties that must be considered to provide the answers and, finally, reinforces the idea that time should be considered by the respondent (30 day-interval preceding the interview). The flash-card \#2 shows a scale of 1 to 5 , associating the score with categories ranging from none to the maximum difficulty in the execution of a determined action.

In this version, it is noticeable that WHODAS introduces different forms of graphical standardization (bold,italic, and blueand standard types).The WHODAS Manual presents all information about typographic conventions, which are the same for all versions of the questionnaire. It is necessary rigor in the application of the instrument, by clinicians or researchers who use this tool, that these typographic conventions are respected and their objectives achieved ${ }^{11}$.

\section{Other versions of WHODAS 2.0 and reference standards answers}

The reader will find all the other six questionnaires versions on the $\mathrm{WHO}$ website and, as they are public domain material, no authorization is necessary for their use. However, regardless of which version being used, respondents should follow the benchmarks for the answers. Therefore, the clinical or research user of 
WHODAS should keep in mind that any difficulty reported in the answers should be closely related to his/her health condition. Answers should consider how the respondent usually performs the activity. Thus, items not experienced in the last 30 days (time reference for all questions) are not scored. Finally, if the respondent's health condition oscillates between good and bad days, the average of these days should be considered to qualify the difficulty presented to the asked questions ${ }^{11}$.

\section{Cross-cultural adaptations needed throughout the translation process}

Minimum cross-cultural adaptations were made, attempting to maintain the highest possible fidelity to the original version of the instrument. As example of these adaptations, we cite the translation and adaptation of the expression "relaxation or pleasure", translated as "relaxation or leisure", which is justified by the fact that there is a problem if we translate the original expression, since the item would have a different meaning in the Brazilian context when compared to the English version. Continuing this line of thought, the word "carer", present in the 36-itens version applied to the proxy was translated as "person who is cared by you", considering that the translation of the word is impossible since there is no equivalent word or term in Brazilian Portuguese. In a similar case, the word "proxy" was not translated because it does not exist an equivalent word with the same meaning. The maintenance of this specific term in its original form follows the trend of other authors who have also made this choice in national publications ${ }^{12}$.

\section{DISCUSSION}

The information about the WHODAS 2.0 is presented very briefly and is not, in any way, sufficient to exhaust the recommendations set by WHO regarding the application of the instrument. This underscores once again the importance of the WHODAS Manual reading, translated and cross-culturally adapted for the use in Brazil ${ }^{11}$. In this Manual, the user will find guidance on the most appropriate ways of dealing with lost data; how to get the total score and domains; and other highly relevant practical information applicable to each of the versions of the instrument.
The translation of WHODAS to the Brazilian Portuguese required minimum cross-cultural adaptation, which is justified by the project planning process that originated the instrument. WHODAS was developed based on cross-cultural studies undertaken in 19 countries around the world. The researchers carefully included items in the instrument, only after consideration of its nature and practice in different cultures, following a single set of applicability cross-cultural study protocols aiming to ensure that WHODAS had a high degree of functional and metric equivalence between different cultures and environments ${ }^{11}$.

As WHODAS is a generic instrument, developed to assess the functioning of people with and without a health condition, it is up to researchers who now use it to proceed the validation studies and to check its psychometric properties. Thus, it would ensure the reliability and validity of the resulting functional assessment of this instrument implementation for certain samples of individuals.

Being a generic instrument that was based on a solid theoretical basis, with good psychometric properties, allowing application in distinct groups and environments, with ease of use, the WHODAS application should be encouraged in the different health areas, both in clinical and research fields. Besides, WHODAS fills a gap on the standardization of the information collection on human functioning by providing a consistent tool with the ICF model, with encouragement and support from WHO.

As already stressed, WHODAS 2.0 is a generic instrument that assesses health and functioning through a numerical score and can be applied in populational and clinical settings for people who have the most diverse health conditions. Furthermore, the Manual available along with the WHODAS instrument also brings content that reinforces the idea of treating the functioning as a continuous process, replacing the dualistic or dichotomous strategy to characterize the conditions set by the individual through the opposite words "health" and "disability", implementing a dynamic vision that translates disability as a reduction of functioning, due to other components of the ICF explanatory model such as injuries, activity limitations and participation restrictions (related to disability), and body functions and structures, activities and participation (related to improvement of functioning). This approach advances the understanding of human functioning in its various nuances and variations, by 
understanding this concept as a dynamic and variable process. Such approach would accommodate more satisfactorily the functional variations that subjects with the same health condition can present.

It should be also noted that the continued use of the instrument versions could expose processes and points to be improved in fields such as writing, formatting, and application of the instruments. It is expected that the various stakeholders report their comments to $\mathrm{WHO}$ for the continuously improvement of the material.

\section{CONCLUSION}

The Brazilian version of WHODAS is finalized, approved by WHO and ready to use by researchers and clinicians in Brazil. Subsequent validation studies in diverse population segments should be encouraged and implemented.

\section{ACKNOWLEDGEMENT}

Very special thanks to Mr. Mark Ross for reviewing the English style of the manuscript.

\section{REFERENCES}

1. Organização Mundial da Saúde. CIF: Classificação Internacional de Funcionalidade, Incapacidade E Saúde. São Paulo: Edusp; 2003.

2. Altman BM, Gulley SP. Convergence and divergence: differences in disability prevalence estimates in the United States and Canada based on four health survey instruments. Soc Sci Med. 2009;69(4):543-552. doi: 10.1016/j. socscimed.2009.06.017

3. McDermott S, Turk MA. The myth and reality of disability prevalence: measuring disability for research and service. Disabil Health J. 2011;4(1):1-5. doi: 10.1016/j.dhjo.2010.06.002
4. Altman BM. A reply to: the myth and reality of disability prevalence: measuring disability for research and service. Disabil Health J. 2011;4(3):198-9. doi: 10.1016/j. dhjo.2011.04.002

5. Di Nubila HBV, Buchalla CM. O papel das Classificações da OMS - CID e CIF nas definições de deficiência e incapacidade. Rev Bras Epidemiol. 2008;11(2):324-35. doi: 10.1590/ S1415-790X2008000200014

6. Kostanjsek N. Use of The International Classification of Functioning, Disability and Health (ICF) as a conceptual framework and common language for disability statistics and health information systems. BMC Public Health. 2011;11(Suppl 4):S3. doi: 10.1186/1471-2458-11-S4-S3

7. Brunani A, Raggi A, Sirtori A, Berselli ME, Villa V, Ceriani F, et al. An ICF-Based Model for Implementing and Standardizing Multidisciplinary Obesity Rehabilitation Programs within the Healthcare System. Int J Environ Res Public Health. 2015;12(6):6084-91. doi: 10.3390/ijerph120606084

8. Üstün B, Chatterji S, Kostanjsek N. Comments from who for the journal of rehabilitation medicine special supplement on ICF core sets. J Rehabil Med. 2004;36(Suppl. 44):7-8. doi: 10.1080/16501960410015344

9. Organização Mundial da Saúde. Checklist da CIF. Brasília, DF: OMS; 2003. [cited 2017 jun 21]. Available from: http://www. fsp.usp.br/cbcd/wp-content/uploads/2015/11/LISTA-DECONFERE\%CC\%82NCIA-DA-CIF-2004.pdf

10. Üstün TB, Kostanjsek N, Chatterji S, Rehm J. Measuring Health and Disability: Manual for WHO Disability Assessment Schedule (WHODAS 2.0). Malta: World Health Organization; 2010.

11. Castro SS, Leite CF, editores. Avaliação de saúde e deficiência: manual do WHO disability assessment schedule (WHODAS 2.0). Uberaba: Universidade Federal do Triângulo Mineiro; 2015. [cited 2017 Ju 21]. Available from: http://apps.who.int/iris/ bitstream/10665/43974/19/9788562599514_por.pdf

12. Jardim R, Barreto SM, Giatti L. Confiabilidade das informações obtidas de informante secundário em inquéritos de saúde. Cad Saude Publica. 2010;26(8):1537-48. doi: 10.1590/ S0102-311X2010000800008 